\title{
Neostigminin başarısız olduğu roküronyuma bağlı rezidüel kürarizasyonda Sugammadeks kullanımı
}

\section{Sugammadex usage for rocuronium caused residual curarization in which neostigmine failed}

\author{
Kasım Tuzcu*, Işıl Davarcı, Murat Karcıoğlu, Yusuf Bolkan Bozdoğan, Suzan \\ Aydın, Leyla Kekeç
}

Anesteziyoloji ve Reanimasyon Anabilim Dalı (Yrd. Doç. Dr. K. Tuzcu, Yrd. Doç. Dr. I. Davarcı, Yrd. Doç. Dr. M. Karcıoğlu, Dr. Y. B. Bozdoğan, Dr. S. Aydın, Dr. L. Kekeç), Mustafa Kemal Üniversitesi Tıp Fakültesi, TR-31000 Antakya

\section{Özet}

Nondepolarizan kas gevşetici ajanların etkilerinin uzamasına bağlı olarak gelişen postoperatif rezidüel kürarizasyon modern anestezide hala yaygın görülen ve hasta güvenliğine ciddi tehdit oluşturan önemli bir problemdir. Anestezi sonrasında rezidüel nöromusküler blok, uygun şekilde döndürülmezse postoperatif pulmoner komplikasyonların gelişimini ve postoperatif mortaliteyi arttırır. Spinal kitle nedeniyle opere edilen Amerikan Anestezistler Derneği II risk grubu olgumuzda nöromusküler bloker olarak roküronyum kullanıldı. Operasyonun sonunda roküronyuma bağlı rezidüel nöromusküler bloğu döndürmek için neostigmin kullanılmasına rağmen hastada solunum yetmezliği gelişti. Kas gücü yetersiz olan hasta ajite, taşikardik, takipneik ve tidal volümü düşüktü. Postoperatif rezidüel kürarizasyonu döndürmede neostigminin başarısız olması üzerine, hastaya modifiye $\gamma$ - siklodekstrin yapısındaki $200 \mathrm{mg}$ sugammadeks uygulandi. Nöromusküler bloğun hızlı ve etkili bir şekilde döndüğü tespit edildi. Sonuç olarak geleneksel antikolinerjik ajanların başarısız olduğu roküronyuma bağlı rezidüel kürarizasyonda sugammadeks kullanımının güvenilir ve etkin olduğunu düşünüyoruz.

Anahtar sözcükler: Sugammadeks, Neostigmin, Rezidüel kürarizasyon

\begin{abstract}
Postoperative residual curarization caused by prolonged effect of non-depolarizing neuromuscular blocking agents is still a serious, frequent and life threatening problem in modern anesthesia. If postoperative residual neuromuscular block cannot be recovered properly, postoperative pulmonary complications and mortality may increase. We used rocuronium as a neuromuscular blocker in our American Society of Anesthesiologists II risked patient which was operated for a spinal mass. Respiratory failure was occurred in our patient despite the usage of neostigmine for recovering neuromuscular block caused by rocuronium. The patient was tachycardic, tachypneic, the tidal volume was decreased and the muscle strength was weak. After the ineffectiveness of neostigmine in recovering neuromuscular blockage, 200mg sugammadex which is a modified $\gamma$ cyclodextrin was given to the patient. We observed that neuromuscular blockage was recovered rapidly and effectively. In conclusion, we think that using sugammedex is effective and safe in residual curarization caused by rocuronium in which traditional anticholinergic agents are not successful.
\end{abstract}

Keywords: Sugammadex, neostigmine, residual curarization

Geliş tarihi/Received: 20 Aralık 2011; Kabul tarihi/Accepted: 3 Mayıs 2012

\section{*İletişim adresi:}

Dr. Kasım Tuzcu, Anesteziyoloji ve Reanimasyon Anabilim Dalı, Mustafa Kemal Üniversitesi Tıp Fakültesi, TR-31000 Antakya. E-posta: tuzcu01@gmail.com 


\section{Giriș}

Nondepolarizan kas gevşetici ajanların etkilerinin uzamasına bağlı olarak gelişen postoperatif rezidüel kürarizasyon modern anestezide hala yaygın görülen ve hasta güvenliğine ciddi tehdit oluşturan önemli bir problemdir [1]. Günümüzde geleneksel dekürarizasyon için kolinesteraz inhibitörü ajanlar muskarinik antagonistlerle kombine edilerek yaygın olarak kullanılmaktadır. Bununla birlikte derin nöromusküler bloğun döndürülmesinde kolinesteraz inhibitörleri etkisizdir. Ayrıca bu ilaçların istenmeyen kardiyovasküler, solunumsal ve kolinerjik yan etkileri sık görülür [2-4]. Son yıllarda steroid yapıdaki nöromusküler bloker ajanlarda modifiye $\gamma$-siklodekstrin yapısındaki sugammadeks kullanılarak, kolinesteraz inhibitörleri ile yapılan geleneksel dekürarizasyon işlemine güncel bir alternatif sunulmaktadır [3-5]. Bu sunumda geleneksel antikolinerjik ajanların başarısız olduğu roküronyuma bağlı rezidüel kürarizasyonda sugammadeks kullanımının güvenliği ve etkinliği tartışıldı.

\section{Olgu}

Hastaneye geliş nedeni şiddetli bel ağrısı ve sağ uyluk ön yüzünde uyuşma şikayetleri olan 52 yaşında, $90 \mathrm{~kg}$ ağırlığında erkek hastanın, çekilen lomber MR tetkikinde L3-L4 intervertebral disk seviyesinde filum terminalede yaklaşık $13 \times 7 \mathrm{~mm}$ boyutlarında tüm sekanslarda hipointens izlenen, kalsifik olduğu düşünülen kitlesi olduğu görüldü. Hastaya spinal kitle tanısı konularak elektif cerrahisi planlandı. Anamnezinde 17 yıllık hepatit B taşıyıcısı olduğu ve günlük düzenli olarak alkol kullanma alışkanlığı olduğu öğrenildi. Tetkiklerinde hafif SGPT (serum glütamik pivürik transaminaz) yüksekliği (51 U/L) dışında herhangi bir patolojik bulgu yoktu. Genel anestezi uygulaması için bilgilendirilmiş onamı alınan hastanın fiziksel durumu ASA (American Society of Anesthesiologists) II olarak belirlendi. Operasyon odasina alınan hastanın elektrokardiyogram, invaziv sistemik arter kan basinc1, periferik oksijen satürasyonu $\left(\mathrm{SpO}_{2}\right)$ ve idrar sondası ile monitörizasyonu yapıldı. K1sa boyunlu olan hastada zor entübasyon ihtimali düşünülerek anestezi indüksiyonu sırasıyla $40 \mathrm{mg}$ aritmal, $100 \mu \mathrm{g}$ fentanil, $180 \mathrm{mg}$ propofol ve $100 \mathrm{mg}$ süksinil kolin ile yapıldı. Sekiz buçuk mm iç çaplı spiralli tüp ile entübasyon yapıldı. Her iki hemitoraksın eşit olarak havalandığı saptandıktan sonra entübasyon tüpünün derinliği diş hizasında $18 \mathrm{~cm}$ olarak tespit edildi. Hastanın tidal volümü $600 \mathrm{ml}$, dakikada solunum sayısı 12 olarak belirlendi. End-tidal $\mathrm{CO}_{2}$ değeri 30-40 mmHg arasında tutuldu. Anestezi idamesinde inspiratuvar \% $40 \mathrm{O}_{2}+$ $\% 60 \mathrm{~N}_{2} \mathrm{O}$ içinde \%2 konsantrasyonunda sevofluran kullanıldı. Hasta süksinil kolini y1ktıktan sonra kas gevşemesi için $50 \mathrm{mg}$ roküronyum yükleme dozu yapı1ıp, $5 \mu \mathrm{g} / \mathrm{kg} / \mathrm{dk}$ infüzyona başlandı. Pron pozisyonunda yapılan operasyonun bitiminden on beş dakika önce roküronyum infüzyonu kesildi. Operasyon 3,5 saat sürdü. Operasyon boyunca hastanın hemodinamisi stabil seyretti. Hastaya total $2000 \mathrm{~mL}$ kristaloid, $500 \mathrm{~mL}$ kolloid mai verildi. $500 \mathrm{~mL}$ idrar çıkardı. Operasyonun sonunda hastanın spontan solunum eforu başladıktan sonra düşük konsantrasyonda gönderilen sevofluran ve $\mathrm{N}_{2} \mathrm{O}$ kesilip, $\% 100 \mathrm{O}_{2}$ akımına geçildi. Bolus dozda yavaşca $35 \mu \mathrm{g} / \mathrm{kg}$ neostigmin ve $15 \mu \mathrm{g} / \mathrm{kg}$ atropin yapıldı. Neostigmin yapıldıktan $15 \mathrm{dk}$ sonra spontan solunum olmasına rağmen hala tidal volümü düşük (yaklaşık $150 \mathrm{~mL}$ ), taşikardik (120 atım/dk) ve takipneik (solunum sayısı dakikada 25 civarında) idi. Bu nedenle $15 \mu \mathrm{g} / \mathrm{kg}$ ek doz neostigmin uygulandı. Taşikardisi ve takipnesi devam eden hasta, \%100 $\mathrm{O}_{2}$ ile spontan solunumu desteklendiği için $\mathrm{SpO}_{2}$ 'si \% 96 olmasına rağmen gözlerini açamıyor, yutkunamıyor ve kollarını kaldıramıyordu. Ajitasyon ve hipertansiyon (210/125 mmHg) gelişmesi üzerine $5 \mu \mathrm{g} / \mathrm{kg} / \mathrm{dk}$ propofol ile sedasyon başlandı. Kliniği düzelmeyen hastaya, neostigmin yapıldıktan 45 dakika sonra temin edilen sugammadeks $200 \mathrm{mg}$ (yaklaş1 $2 \mathrm{mg} / \mathrm{kg}$ ) iv bolus uygulandı. Sugammadeks injeksiyonundan 30 sn sonra tidal volümleri $450 \mathrm{~mL}$ 'nin üzerine çıkan hastanın inspirasyon gücü $-25 \mathrm{~cm} \mathrm{H}_{2} \mathrm{O}$ olması üzerine 90 saniye sonra ekstübe edildi. Ekstübe edildikten sonra akut solunum yetmezliği ve rezidüel bloğu düşündürecek kas güçsüzlüğü yok idi (Tidal volum $500 \mathrm{~mL}$, dakikadaki solunum sayısı 18 idi). Başını ve kollarını $5 \mathrm{sn}$ kaldırabiliyordu. Gözlerini açtı. Dilini çıkardı. Postoperatif uyanma odasında bir saat 
takip edilen hastanın vital bulguların stabil olması, $\mathrm{SpO}_{2}$ 'nin $\% 97$ olması ve kas gücünün yerinde olması üzerine servisine gönderildi.

\section{Tartışma}

Nöromusküler bloker ajanlar modern anestezinin önemli bir parçasıdır. Kas gevşeticilerin kullanılmas1 istemli ve refleks kas hareketlerini baskılayarak daha uygun entübasyon koşulları sağlar. Ayrıca daha az anestezik madde gereksinimi altında cerrahi girişim için yeterli kas gevşemesi elde edilir [5, 6]. Bununla birlikte nöromusküler bloker kullanılan operasyonlarda rezidüel kürarizasyon riski vardır. Anestezi sonrasında nöromusküler kavşak yeterli düzeyde derlenmezse postoperatif pulmoner komplikasyonların gelişimi ve mortalite artar [4, 7]. Günümüzde geleneksel olarak neostigmin ve piridostigmin gibi kolinesteraz inhibitörleri, nöromusküler bloker ajanların etkisini antagonize etmek için kullanılır. Son yıllarda ise roküronyum ve veküronyum gibi steroid yapıdaki nöromusküler bloker ajanların yaptığı nöromusküler bloğun antagonizasyonunda kullanılan spesifik siklodekstrin olan sugammadeks geliştirilmiştir [3-5]. Saçan ve ark. [3] roküronyuma bağlı rezidüel nöromusküler bloğun antagonizasyonunda sugammadeks (4 mg/kg IV), neostigmin (70 $\mu \mathrm{g} / \mathrm{kg} \mathrm{IV})$ ve edrofonyumu ( $1 \mathrm{mg} / \mathrm{kg} \mathrm{IV})$ karşılaştırdıkları çalışmalarında sugammadeksin çok daha hızlı ve etkili olduğu sonucuna ulaşmışlardır. Bununla uyumlu olarak roküronyumun neden olduğu rezidüel nöromusküler blok da neostigminle sugammadeksin karşılaştırıldı ğ 1 birçok çalışmada da benzer sonuçlar elde edilmiştir [5, 8, 9]. Sugammadeksin etki mekanizması incelendiğinde plazmadaki roküronyum moleküllerini enkapsüle ederek motor son plaktaki nikotinik reseptördeki roküronyum moleküllerinin sayısını hızla azalttığı görülür. Böylece kas aktivitesinin kısa sürede geri dönmesini sağlar. Neostigmin ise nöromusküler bloker ajanların farmakolojik bir antagonisti değildir. Asetilkolin esterazı inhibe ederler ancak nöromusküler bloker ajanları elimine edemezler. Artan asetilkolin konsantrasyonu roküronyumu reseptörlerden tam olarak ayırmak için yetersizdir. Bu nedenle klinikte etkileri daha yavaş ortaya çıkar [4, 10]. Lenz ve ark. [11] $10 \mathrm{mg}$ veküronyum kullandıkları kronik böbrek yetmezliği hastasında nöromusküler bloğu antagonize etmek için $5 \mathrm{mg}$ neostigmin ve $1 \mathrm{mg}$ glikopirolat kullanmalarına rağmen bloğu tam olarak antagonize edememişler ve hastada rezidüel nörömusküler bloğa bağl1 akut solunum yetmezliği gelişmiştir. Hastaya $350 \mathrm{mg}$ IV sugammadeks $(4 \mathrm{mg} / \mathrm{kg})$ uygulandıktan $60 \mathrm{sn}$ sonra tidal volüm düzelmiş, $2 \mathrm{dk}$ sonra ise trakeal ekstübasyon uygulanmıştır. Bizim çalışmamızda ameliyat bittikten sonra spontan solunum eforu başlayan hastaya yaklaş1k $5 \mathrm{mg}$ neostigmin ve $1,5 \mathrm{mg}$ atropin uyguland1. Buna rağmen tidal volümü yeterli miktara ulaşmayan hastada ajitasyon, taşikardi, takipne ve hipertansiyon gelişmesi üzerine, propofolle sedasyon uygulamasına başlandı. Neostigmin ile nöromusküler bloker ajanların etkisinden kurtulamayan hastaya, $200 \mathrm{mg}$ IV sugammadeks (yaklaşı $2 \mathrm{mg} / \mathrm{kg}$ ) uygulandı. Yaklaşık $30 \mathrm{sn}$ sonra tidal volümleri düzelmeye başlayan hasta 90 sn sonra ekstübe edildi. Olgumuzda potent bir inhalasyon anesteziği olan sevofluranla beraber, kaliteli ve sürekli bir kas gevşemesi elde etmek için roküronyumu infüzyon şeklinde uygulandı. Buna bağlı olarak nöromusküler bloğun uzadığını, neostigminin etkisiz kaldığını düşünüyoruz. Bununla birlikte sugammadeks, olgumuzda nöromusküler bloğu hızlı bir şekilde geri döndürdü. Birçok çalışmada da bildirildiği gibi sugammadeksin inhalasyon ajanlarından etkilenmediğini ve hem derin hem de yüzeyel nöromusküler blokta etkili olduğunu düşünüyoruz $[10,12,13]$. Naguib ve ark. [14] çalışmalarında intraoperatif nöromusküler fonksiyonların monitörizasyonunun postoperatif rezidüel blok insidansını azaltmadığı fakat orta etkili nöromusküler bloker ajan kullanımının postoperatif rezidüel blok insidansını azalttığını bildirmişlerdir. Bununla birlikte Gatke ve ark. [15] orta etkili bir kas gevşetici ajan olan roküronyuma bağlı rezidüel bloğun nöromusküler monitörizasyonla minimalize edilebileceğini bildirmişlerdir. Bizim olgumuzda hem intraoperatif nöromusküler monitörizasyon uygulanmamasının hem de orta etkili bir kas gevşetici olmasına rağmen roküronyumun infüzyon şeklinde kullanılmasının postoperatif rezidüel bloğa neden olabileceğini düşünüyoruz. Bir çalışmada kaza ile $40 \mathrm{mg} / \mathrm{kg}$ sugammadeks verilen hastanın takibinde kalp hızında, kan basıncında ve elektrokardiyografisinde herhangi bir 
değişiklik gözlenmemiştir. Postoperatif 7 gün boyunca izlenen hastanın hematolojik ve biyokimya değerlerinde herhangi bir anormallik olmayıp renal ve karaciğer fonksiyonlarında bir değişiklik gözlenmemiştir [16]. Roküronyuma bağlı nöromusküler blokta sugammadeks kullanılan birçok çalışmada bradikardi, bronkokonstriksiyon, hipersalivasyon, abdominal kramplar, bulantı ve kusma gibi kolinesteraz inhibitörü kullanımına bağlı yan etkiler olmaksızın hızlı ve etkili bir geri dönüş olduğu gözlenmiştir $[3,10,12,13]$. Sugammadeksin başlica yan etkileri olarak dysgeusia (tat alma bozukluğu), diyare ve kalp hızında hafif bir azalma olduğu bildirilmiştir [17-19].

Sonuç olarak roküronyuma bağlı nöromusküler bloğun geri döndürülmesinde sugammadeks yeni bir alternatiftir. Kolinesteraz inhibitörleri ile karşılaştırıldığında ciddi bir yan etkisi yoktur. Neostigminin başarısız olduğu rezidüel kürarizasyonda kullanımının etkili ve güvenli olduğunu düşünüyoruz.

\section{Kaynaklar}

1. Naguib M, Kopman AF, Lien CA, Hunter JM, Lopez A, Brull SJ. A survey of current management of neuromuscular block in the United States and Europe. Anesth Analg 2010; 111: 110-9.

2. Kim KS, Lew SH, Cho HY, Cheong MA. Residual paralysis induced by either vecuronium or rocuronium after reversal with pyridostigmine. Anesth Analg 2002; 95: 1656-60.

3. Sacan O, White PF, Tufanogulları B, Klein K. Sugammadex reversal of rocuronium-induced neuromuscular blockade: a comparison with neostigmineglycopyrrolate and edrophonium-atropine. Anesth Analg 2007; 104: 569-74.

4. Flockton EA, Mastronardi P, Hunter JM, Gomar C, Mirakhur RK, Aguilera L, Giunta FG, Meistelman C, Prins Me. Reversal of rocuronium-induced neuromuscular block with sugammadex is faster than reversal of cisatracuriuminduced block with neostigmine. Br J Anaesth 2008; 100: 622-30.

5. Blobner M, Eriksson LI, Scholz J, Motsch J, Della Rocca G, Prins ME. Reversal of rocuronium-induced neuromuscular blockade with sugammadex compared with neostigmine during sevoflurane anaesthesia: results of a randomised, controlled trial. Eur j Anaesthesiol 2010; 27: 874-81.

6. Claudius C, Garvey LH, Viby-Mogensen J. The undesirable effects of neuromuscular blocking drugs. Anaesthesia 2009; 64 Suppl 1: 10-21.

7. Murphy GS, Szokol JW, Marymont JH, Greenberg SB, Avram MJ, Vender JS. Residual neuromuscular blockade and critical respiratory events in the postanesthesia care unit. Anesth Analg 2008; 107: 130-7.

8. Illman Hl, Laurila P, Antila H, Meretoja OA, Alahuhta S, Olkkola KT. The duration of residual neuromuscular block after administration of neostigmine or sugammadex at two visible twitches during train-of-four monitoring. Anesth Analg 2011; 112: 63-8.

9. Paton F, Paulden M, Chambers D, Heirs M, Duffy S, Hunter JM, Sculpher M, Woolacott N. Sugammadex compared with neostigmine/glycopyrrolate for routine reversal of neuromuscular block: a systematic review and economic evaluation. Br J Anaesth 2010; 105: 558-67.

10. De Boer HD. Neuromuscular transmission: new concepts and agents. J Crit Care 2009; 24: 36-42.

11. Lenz A, Hill G, White PF. Emergency use of sugammadex after failure of standard reversal drugs. Anesth Analg 2007; 104: 585-6.

12. Della Rocca G, Pompei L. A novel approach to reversal of neuromuscular blockade. Minerva Anestesiol 2009; 75: 349-51.

13. Brull SJ, Naguib M. Selective reversal of muscle relaxation in general anesthesia: focus on sugammadex. Drug Des Devel Ther 2009; 3: 119-29.

14. Naguib M, Kopman AF, Ensor JE. Neuromuscular monitoring and postoperative residual curarisation: a meta-analysis. Br J Anaesth 2007; 98: 302-16. 
15. Gätke MR, Viby-Mogensen J, Rosenstock C, Jensen FS, Skovgaard LT. Postoperative muscle paralysis after rocuronium: less residual block when acceleromyography is used. Acta Anaesthesiol Scand 2002; 46: 207-13.

16. Molina AL, de Boer HD, Klimek M, Heeringa M, Klein J. Reversal of rocuronium-induced (1.2 mg kg-1) profound neuromuscular block by accidental high dose of sugammadex (40 mg kg-1). Br J Anaesth 2007; 98: 624-7.

17. De Boer HD, Driessen JJ, Marcus MA, Kerkkamp H, Heeringa M, Klimek M. Reversal of rocuronium-induced $(1.2 \mathrm{mg} / \mathrm{kg})$ profound neuromuscular block by sugammadex: a multicenter, dose-finding and safety study. Anesthesiology 2007; 107: 239-44.

18. Dahl V, Pendeville PE, Hollmann MW, Heier T, Abels EA, Blobner M. Safety and efficacy of sugammadex for the reversal of rocuronium-induced neuromuscular blockade in cardiac patients undergoing noncardiac surgery. Eur J Anaesthesiol 2009; 26: 874-84.

19. Menéndez-Ozcoidi L, Ortiz-Gómez JR, Olaguibel-Ribero JM, Salvador-Bravo MJ. Allergy to low dose sugammadex. Anaesthesia 2011; 66: 217-9. 